\title{
TEM observation of twin evolution in austenitic TWIP steel
}

\author{
JungHoon Han, Miyoung Kim and Heung Nam Han
}

Department of Materials Science and Engineering, Seoul National University, Sillim 9-dong Gwanak-gu Seoul 151-744, Korea

High manganese austenitic twinning induced plasticity (TWIP) steel is well known for its high strength and good ductility. Therefore, this steel has gained attention as a candidate for automotive applications [1]. These properties stem from the generation of crystallographic slip and mechanical twinning [2]. Twin variant, including twin plane and twin direction, has an influence on texture of austenite phase, which is one of the most crucial factor for determining strength and ductility. Researches on TWIP steel include strain hardening rate, mechanical properties, plastic strain and twinning mechanism. In this study, microstructure and twin variant selection of the high manganese TWIP steel under directional strain are investigated by using transmission electron microscopy (TEM).

The high manganese TWIP steel specimens, for this experiment, have the austenitic structure at room temperature. Tensile test specimen of $25 \mathrm{~mm}$ in gauge length and $6.25 \mathrm{~mm}$ in diameter is machined from a bulk sample. Tensile specimens were deformed into four states, 10\%, 20\%, 30\% strained and fractured, respectively. Thin foils for TEM were taken out from the center part of the deformed specimens within gauge length, and prepared in a twin-jet electrolytic polishing apparatus using a solution containing 10\% perchloric acid and 90\% ethanol. The microstructures of the steel were observed by using a transmission electron microscope (3000F, JEOL) with an operation voltage of $300 \mathrm{kV}$. In this work, twin plane and twin direction are examined with TEM images and diffraction patterns (DP) as shown in Fig. 1.

Austenite twins on $\{111\}<11-2>$ system have 12 variants in any one austenite grain, as shown in Table 1 [3]. The interaction energy between externally applied stress and lattice deformation has been calculated for each 24 Kurdjumov-Sachs (K-S) variants and the probability of variant selection is assessed in the transformation induced plasticity (TRIP) steel [4]. The same method is applied to the TWIP steel in order to obtain the interaction energy between externally applied stress and lattice deformation for each 12 twin variants and to access the probability of variant selection. The assessed probability will be compared with the experimental results. When the TWIP steel specimens are deformed, twins occur to the most favorable direction along the tensile direction as shown in Fig. 2. Twin evolution in the tensile behavior will be proposed.

\section{References}

[1] S.Allain et al., Materials Science and Engineering, A389-389 (2004) 143.

[2] Bouaziz O et al., Materials Science and Engineering, A319-321 (2001) 246-249.

[3] B. Qin et al., Materials Science and Technology, Vol.24 (2008) No8 969.

[4] Seung Hyun LEE et al., ISIJ International, Vol.45 (2005) No8 1217-1219.

[5] This work was supported by the Korea Science and Engineering Foundation (KOSEF) grant funded by the Korea government (MOST) (ROA-2007-000-10014-0(2008)). 
TABLE 1. The twelve independent mechanical twinning systems in austenite

\begin{tabular}{|c|c|}
\hline No. & Twin variant \\
\hline 1 & $\left(\begin{array}{lll}1 & 1 & 1\end{array}\right)\left[\begin{array}{lll}1 & 1 & -2\end{array}\right]$ \\
\hline 2 & $\left(\begin{array}{lll}1 & 1 & 1\end{array}\right)\left[\begin{array}{lll}1 & -2 & 1\end{array}\right]$ \\
\hline 3 & $\left(\begin{array}{lll}1 & 1 & 1\end{array}\right)\left[\begin{array}{lll}-2 & 1 & 1\end{array}\right]$ \\
\hline 4 & $\left(\begin{array}{lll}1 & -1 & -1\end{array}\right)\left[\begin{array}{lll}1 & -1 & 2\end{array}\right]$ \\
\hline 5 & $\left(\begin{array}{lll}1 & -1 & -1\end{array}\right)\left[\begin{array}{lll}1 & 2 & -1\end{array}\right]$ \\
\hline 6 & $\left(\begin{array}{lll}1 & -1 & -1\end{array}\right)\left[\begin{array}{lll}-2 & -1 & -1\end{array}\right]$ \\
\hline 7 & $\left(\begin{array}{lll}-1 & 1 & -1\end{array}\right)\left[\begin{array}{lll}-1 & 1 & 2\end{array}\right]$ \\
\hline 8 & $\left(\begin{array}{lll}-1 & 1 & -1\end{array}\right)\left[\begin{array}{lll}-1 & -2 & -1\end{array}\right]$ \\
\hline 9 & $\left(\begin{array}{lll}-1 & 1 & -1\end{array}\right)\left[\begin{array}{lll}2 & 1 & -1\end{array}\right]$ \\
\hline 10 & $\left(\begin{array}{lll}-1 & -1 & 1\end{array}\right)\left[\begin{array}{lll}-1 & -1 & -2\end{array}\right]$ \\
\hline 11 & $\left(\begin{array}{lll}-1 & -1 & 1\end{array}\right)\left[\begin{array}{lll}-1 & 2 & 1\end{array}\right]$ \\
\hline 12 & $\left(\begin{array}{lll}-1 & -1 & 1\end{array}\right)\left[\begin{array}{lll}2 & -1 & 1\end{array}\right]$ \\
\hline
\end{tabular}
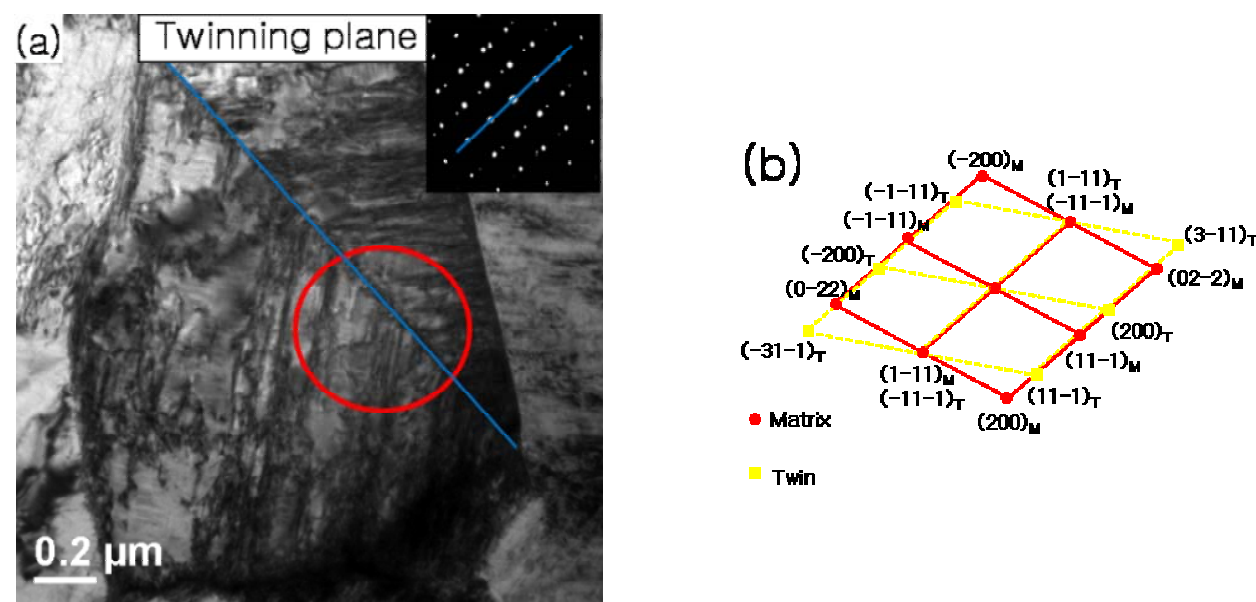

Twin

FIG. 1. (a) BF image and DP image of twin (Blue-line is twinning plane) (b) Simulated SAD pattern of red circle area of (a) (FCC, Zone 0-1-1).

(a)

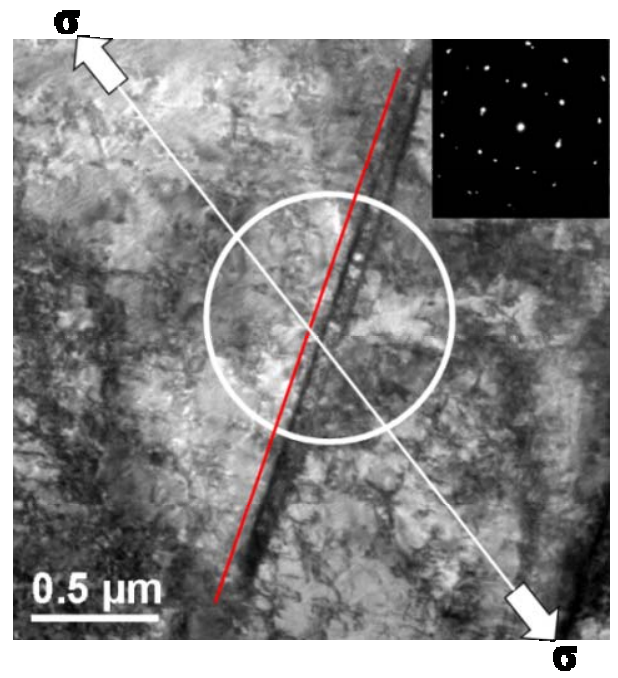

(b)

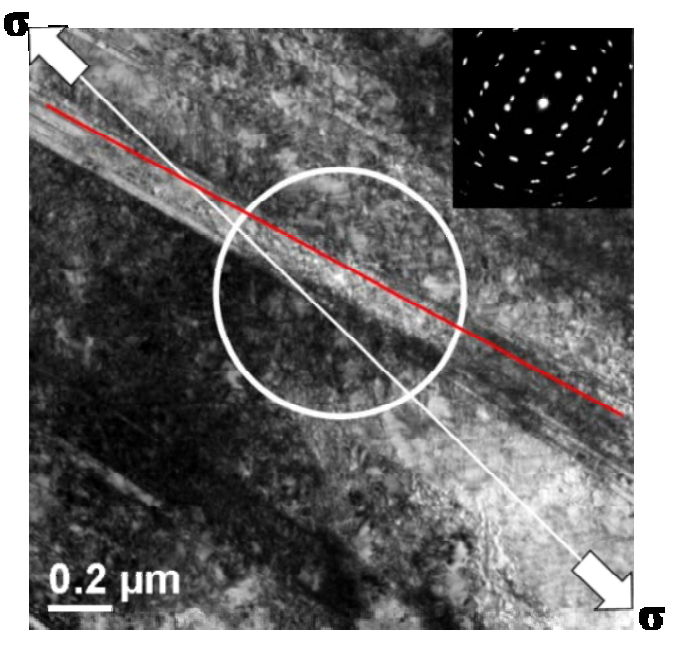

FIG. 2. The BF image and SAD pattern of circle area (Red line is twinning plane, $\sigma$ is tensile direction, FCC, Zone 0-1-1) (a) 10\% strain (b) 30\% strain. 